\title{
Las acciones de garantía bancaria en derecho romano clásico
}

\author{
VICTORIANO SÁIZ LÓPEZ
}

En el estudio de las acciones derivadas de la garantía bancaria, en derecho clásico, tuvo una singular relevancia y aceptación la posición mantenida en su tiempo por Lenel. ${ }^{1}$ Posteriormente, teniendo presente la escasez de datos de las fuentes e incluso el carácter contradictorio de los mismos, como ha subrayado Rossello, ${ }^{2}$ se ha ido imponiendo la evidencia de que sus conclusiones no pueden considerarse convincentes, al apoyarse en bases científicamente poco consistentes.

La aportación que pretendemos hacer aquí consiste fundamentalmente en el desarrollo razonado de una hipótesis que tiene su origen en las conclusiones a que llegó Partsch en sus estudios a propósito de la naturaleza estipulatoria del receptum argentariorum. ${ }^{3}$ Es importante tener también presentes los resultados de las investigaciones posteriores de Astuti en torno a la promesa de pago, que le han llevado a mantener que es posible admitir la identificación de receptum y contrato verbal. ${ }^{4}$

Puede decirse, en general, que los diferentes intentos doctrinales de reconstruir la fórmula recepticia pretenden buscar una solución en el ámbito de las acciones civiles estipulatorias o, como en el caso de Lenel, en los esquemas del edicto pretorio.

Se trata, en este caso, siguiendo la corriente civilista, de plantear una posible reconstrucción de la fórmula clásica de la actio recepticia, formalmente abolida por Justiniano, ${ }^{5}$ que corresponde al acreedor frente al banquero garante $\mathrm{y}$, además, de completar su estudio con el tratamiento de la acción de regreso otorgado al banquero, que paga, frente al deudor principal. 


\section{Acción del acreedor frente al banquero-garante}

Una vez perfeccionada la caución bancaria y si el argentarius no da adecuado cumplimiento de la obligación asumida cuando le es exigida, el acreedor puede interponer una acción y obtener, en su caso, la ejecución de la correspondiente sentencia. Siguiendo la terminología justinianea, puede llamarse esta acción "actio recepticia». ${ }^{6}$ Denominación que, probablemente, no resulta válida en el derecho clásico. En efecto, el adjetivo recepticia no es suficiente para distinguir la reclamación frente al banquero de otras posibles reclamaciones derivadas de receptum. No se califica a la acción atendiendo el criterio del sujeto pasivo sino que se hace a partir de un término genérico que engloba diversos negocios jurídicos. Idénticas consideraciones podemos hacer con respecto a la denominada actio de recepto, relativa a los nautae, para la restitución de las cosas que les fueron confiadas. Esta acción la denomina De Robertis ${ }^{7}$ actio ex recepto, pero también utiliza la expresión actio recepticia, lo que nos da una idea de la falta de precisión terminológica que reina en este campo.

Planteando la cuestión relativa a quienes son los sujetos que activa y pasivamente intervienen en esta acción, parece seguro responder que es el acreedor, y no otros, quien puede hacerla valer frente al banquero. Esto es así porque la aceptación de la obligación la realizaría el segundo ante el primero; ${ }^{8}$ también porque ello se desprende de los textos del Digesto, considerados interpolados. ${ }^{9}$ Por otro lado, esta idea viene confirmada por la relación jurídica existente entre los diversos sujetos que intervienen, de modo directo o indirecto, en el negocio. En efecto, resulta que no está legitimido activamente en la recepticia el deudor principal por las siguientes razones:

Primera.-Si el deudor principal ha encargado al argentarius que asuma la deuda y éste, con posterioridad, no lo hace, habría que recurrir a la acción derivada del mandato.

Segunda.-Es doctrina común que el deudor principal no queda liberado por la promesa bancaria. Se trata del principio de acumulación o de falta de eficacia novatoria. ${ }^{10}$ 
Tercera.-Si el deudor principal ha consignado fondos para el pago en poder del banquero y pretende obtener su restitución puede servirse de una condictio, sin ser necesaria una acción especial.

Cuarta.-Si no ha mediado mandato, el deudor principal no puede utilizar una acción específica frente al banquero, ya que la promesa bancaria no es un contrato del que surgen acciones a favor de terceros. ${ }^{11}$

Esto supuesto, las dificultades se presentan a la hora de reconstruir la fórmula de la llamada a. recepticia, en el derecho romano clásico. En este sentido, se ha de comenzar recordando la opinión de Lenel, quien considera que' la fórmula de la recepticia viene concebida in factum; ${ }^{12}$ partiendo de D. 46, 3, 52 y de D. 12, 2, 27 afirma que, si satisfactio $\mathrm{y}$ iusiurandum equivalen a solutio, en la fórmula recepticia como causa de absolución figuraría únicamente la solutio, aunque junto a ésta también admite la mora del acreedor. Por ello, al igual que ocurre en la fórmula de pecunia constituta, neque fecisse $\mathrm{Nm} \mathrm{Nm}$ quod constituit, neque per Am Am stetisse quo minus fieret quod constitutum est, la recepticia tendría lo siguiente en la cláusla condenatoria: neque solvisse quod solvi recepit, neque per Am Am stetisse quo minus solveretur.

En definitiva, Lenel se inspira, para establecer la fórmula recepticia, en los términos más conocidos de la de pec. const. ${ }^{13}$ Esta idea de considerar la redacción de la fórmula recepticia a imitación de la de pec. const. tiene su fundamento textual en las palabras de Inst. 4, 6, 8, actio de pec. const. cui similis videbatur recepticia.

Sin embargo, no es seguro que este texto de Justiniano lo podamos proyectar sobre el derecho clásico por varios motivos:

Primero.-No se refiere a la a. pec. const. clásica sino a una acción reformada que deriva de un negocio, el constitutum, cuya evolución histórica lo ha llevado a la proximidad con la stipulatio, según se desprende de C. $4,18,2$. De tal modo que el parentesco jurídico de la recepticia no existe con la de pec. const. clásica sino con la de pec. const. justinianea que nada tiene que ver con la anterior. En consecuencia, el texto nos permite acercar la acción del receptum bancario más a las acciones estipulatorias que a la derivada del constitutum clásico. 
Segundo.-El fundamento de Inst. 4, 6, 8 (a. 533) no puede ser otro que C. 4, 18, 2 (a. 531); no el derecho clásico.

Tercero.-Lo único que parece deducirse de C. 4, 18, 2 es que la recepticia, en su tramitación clásica, no es utilizada en Oriente y que ahora queda englobada en una nueva acción a la que se denomina de pec. const. cuyo ámbito ha sido ampliado hasta cubrir la misma extensión que las acciones derivadas de stipulatio.

La hipótesis en virtud de la cual se atribuye a la promesa bancaria y al receptum argentariorum, con arreglo al derecho romano clásico, una tramitación judicial correspondiente a la de las fórmulas estipulatorias tiene su apoyo en la opinión de Partsch, ${ }^{14}$ quien habla de similitud entre receptum y stipulatio, ya que el constitutum es reformado en relación con la abolición del receptum, equiparándolo a la stipulatio. También en el texto paralelo de los Basílicos (26, 3, 2 Heimb. III p. 109) se reproduce la referencia a la stipulatio, mientras que del receptum no se hace mención alguna. Posteriores estudios de Astutitis confirman esta línea de pensamiento. Según este autor, el fin perseguido por la constitución reformadora es la extensión del ámbito de aplicación de la actio pecuniae constitutae; además, en la compilación resulta alterada la típica función que el edicto de pec. const. había cumplido en el sistema clásico. Los bizantinos presentan una acción reipersecutoria y el constitutum debiti como una promesa de pago, es decir, como una figura contractual cuyo objeto es el cumplimiento de una prestación ya debida por una causa precedente, y en paralelo a la stipulatio debiti.

Resulta significativa la insistencia con que en la constitución del 531 se hace referencia a la stipulatio, lo que confirma que es en ésta en la que el emperador está pensando al suprimir las antiguas limitaciones del constitutum. Lo que se persigue es la plena equiparación de esta figura pretoria con la general forma contractual civil. ${ }^{16}$ Probablemente esta equiparación con la stipulatio se enmarca dentro del proceso de evolución de la obligatio verborum, en el que decae su típico requisito formal de la oralidad. Y, por lo que se refiere al requisito de la presencia de las partes, venía siendo posible un simple reconocimiento, ordinariamente escrito de haber realizado el acto, admitiéndose la prueba en 
contrario dentro de muy restringidos límites. En el sistema del derecho justinianeo, en el que el carácter formal de la estipulación se reduce sustancialmente al animus stipulandi y, al mismo tiempo, vienen atenuados los efectos rigurosos de su carácter abstracto, el paralelismo aparece tan acusado que hace muy difícil discernir cuándo estamos ante una stipulatio y cuándo ante un constitutum. ${ }^{17}$

Esto supuesto, conviene ahora hacer un breve recordatorio de las fórmulas que surgen de stipulatio. Para ello, las clasificamos en dos apartados:

Bajo la rúbrica si certum petetur, ${ }^{18}$ el Edicto pretorio ofrece tres fórmulas:

Cuando se ha prometido una cierta suma de dinero. Si paret $\mathrm{Nm}$ $\mathrm{Nm}$ Ao Ao sestertium decem milia dare oportere, iudex $\mathrm{Nm} \mathrm{Nm} \mathrm{Ao}$ Ao sestertium decem milia condemnato, si non paret absolvito.

Cuando se ha prometido una cantidad definida de cosas. Si paret $\mathrm{Nm} \mathrm{Nm}$ Ao Ao tritici Africi optimi modios centum dare oportere, quanti ea res est, tantam pecuniam iudex $\mathrm{Nm} \mathrm{Nm}$ Ao Ao condemnato, etc.

Cuando se ha prometido una cosa individualmente determinada. $\mathrm{Si}$ paret Nm Nm Ao Ao servum Stichum dare oportere, quanti ea res est, tantam pecuniam iudex Nm Nm Ao Ao condemnato, etc.

En otra rúbrica del Edicto que, probablemente, reza si cum eo agatur qui incertum promiserit ${ }^{19}$ aparece la siguiente fórmula: Quod As As de No No incertum stipulatus est, quidquid ob eam rem $\mathrm{Nm} \mathrm{Nm}$ Ao Ao dare facere oportet eius, iudex $\mathrm{Nm} \mathrm{Nm}$ Ao Ao condemnato, etc.

La doctrina que busca una solución para la acción de garantía bancaria dentro del esquema anterior tiene un precedente en Zentner, ${ }^{20}$ quien mantiene la existencia no ya de una fórmula sino de varias, según las diversas causas a que puede obedecer la prestación del banquero. El autor llega a admitir que, en ciertos casos, puede derivar de la promesa bancaria la actio certae creditae pecuniae. ${ }^{21}$ Otra de las fórmulas posibles sería ésta: Quod Ns Ns Ao Ao incertum recepit q. d.r. a. quidquid ob eam rem dare facere oportet, eius Nm Nm Ao Ao condemna, si non paret absolve. Pero, como puede comprobarse, ésta no es más 
que una variante de la fórmula derivada de stipulatio cuando se ha prometido un incertum, especialmente aplicable en los casos de promesa de facere. En vez de incertum stipulatus est se dice incertum recepit.

El desarrollo de la presente teoría lleva a la necesidad de plantear las dos posibilidades recogidas a continuación:

Primera.-Si el banquero hace su promesa solemne con la voluntad expresa de asumir toda la responsabilidad a que hubiere lugar, estamos ante una obligación autónoma y abstracta para cuya exigibilidad ha de recurrirse a una de las fórmulas estipulatorias incluidas bajo la rúbrica edictal si certum petetur, según que se haya prometido dinero, una cantidad de cosas o un objeto individualizado.

Segunda.-Si el banquero hace su promesa solemne sin aceptación expresa de responsabilidad, estamos ante una obligación de garantía accesoria y en la fórmula ha de hacerse constar la circunstancia de que esta garantía se halla conectada con una obligación principal de la que trae causa.

En este segundo supuesto, no nos sirve ninguna de las acciones incluidas bajo la rúbrica si certum petetur porque no son aptas para reflejar los precisos términos en que responde el fiador; no queda, pues, más remedio que recurrir a la acción recogida al amparo de la rúbrica si cum eo agatur qui incertum promiserit. En efecto, contra el demandado fiador procede la acción incierta, seguramente, con alguna variante en su fórmula. ${ }^{22}$ Interesa, ahora, determinar cuál es la cláusula de la fórmula mediante la que se hace constar que el demandado es un fiador, a fin de circunscribir la consumición procesal y evitar que se extienda a otro crédito propio. Este objetivo puede cumplirse introduciendo en la fórmula la praescriptio correspondiente que haga constar la circunstancia referente al carácter incierto de la deuda..$^{23}$

Las características que definen esta acción las podemos concretar del siguiente modo: tiene una fórmula in ius concepta puesto que la condena del demandado se subordina a la condición de que el actor tenga un derecho o pretensión ex iure civili; la praescriptio introducida por el pretor en una acción civil no altera su carácter; no se trata de un iudi- 
cium bonae fidei aunque sea semejante, en cierto modo, a las típicas acciones contractuales por su objeto indeterminado. La lex Rubria de Gallia Cisalpina ${ }^{24}$ presenta unas fórmulas procesales para la cautio damni infecti con un oportere ex fide bona; esta anomalía puede explicarse suponiendo una práctica consistente en introducir los términos ex fide bona en la estipulación y de ahí acabaría pasando a la correspondiente fórmula; ${ }^{25}$ la acción sería transmisible activa y pasivamente a los herederos y no tendría plazo de caducidad. La doctrina ha venido manteniendo, sin discusión, el carácter perpetuo y la transmisibilidad de la acción recepticia $y$, recientemente, se sigue insistiendo en esta dirección. ${ }^{26} \mathrm{El}$ fundamento de esta doctrina ha sido la constitución reformadora de Justiniano que habría extendido a la a. pec. const. estos caracteres temporales de la recepticia; el carácter civil de la acción recepti$v^{27}$ y el carácter reipersecutorio de esta acción (no carácter penal como la a. pec. const., en origen). La perpetuidad parece ser típica de las acciones reipersecutorias por oposición a.las penales. ${ }^{28}$ Sin embargo, estos razonamientos no parecen suficientes puesto que tienen excepciones, particularmente significativas, en relación con el tema que nos ocupa. Así es; el vínculo obligatorio constituido por la sponsio y la fidepromissio se extingue, en virtud de la lex Furia de sponsu, en el plazo de dos años si la garantía se presta en Italia ${ }^{29}$ y no se transmite pasivamente a los herederos, ${ }^{30}$ salvo que se trate de fidepromissio realizada por peregrinus y se apliquen normas distintas de las romanas, propias del ordenamiento correspondiente al sujeto que actúa como fidepromissor. ${ }^{31}$

Todas estas circunstancias hacen reconocer que la cuestión relativa al ámbito temporal de la acción recepticia no admite una solución satisfactoria. Ahora bien, podría considerarse como más probable su transmisibilidad y la no existencia de caducidad, si recurrimos a un argumento de analogía con el régimen jurídico de la fideiussio que, según testimonio de Gayo 3, 120 y 121, no está sujeta a la ley Furia. En definitiva, el restringido ámbito de esta ley parece que permite mantener que la regla general es la perpetuidad y transmisibilidad hereditaria. 


\section{Acción de regreso del banquero-garante frente al deudor principal}

Para completar el cuadro de las acciones, queda por examinar el tema del reembolso a favor del banquero que, pagando, ha liberado al deudor principal y ha de obtener de este último adecuada satisfacción. A tal efecto se hace preciso distinguir tres apartados, que se tratan a continuación.

A) Regreso legal: el fundamento del derecho de regreso del garante frente al deudor principal está en la relación interna que une a ambos; esta relación califica de principal a una obligación y de accesoria a otra. En este sentido, considera Frezza que la primera relación interna sería, históricamente, anterior al mismo contrato de mandato. ${ }^{32}$ En efecto, la relación garante-deudor tendría, en origen, su fundamento en vínculos de carácter social, esto es, en una situación de dependencia que estaría próxima a la clientela.

Este hecho explicaría que el prmer reconocimiento del derecho de regreso tenga su apoyo en la ley. Aquí hay que recordar la ley Publilia que sujeta al deudor principal a una manus iniectio del sponsor que ha pagado el débito, si no es reembolsado en el plazo fijado. ${ }^{33}$

B) Regreso convencional: Gayo 3, 127 refleja el régimen de coexistencia del regreso legal y del regreso negocial; este segundo tiene lugar mediante la actio mandati contraria, con fórmula in factum, cuyo fundamento económico es evitar el injusto empobrecimiento del garante y cuyo fundamento jurídico es la relación interna deudor-garante constitutiva de un contrato de mandato.

No se encuentra en las fuentes un supuesto concreto referido a la relación interna entre deudor-cliente y su banquero; pero, D. 13, 5, 27, considerado interpolado, puede constituir un indicio en este sentido. Piénsese, además, que Labeón llega a conceder una excepción al argentarius, con lo que la relación interna llega, incluso, a condicionar la misma relación jurídica fundamental. A pesar de las dificultades, parece una hipótesis bien fundada la que establece que entre banquero y deudor, ordinariamente, mediaría un contrato de mandato que es el sólido fundamento jurídico sobre el que se apoya la acción de regreso del argentarius. $^{34}$ 
Esto supuesto, si se lee D. 17, 1, 6, $2^{35}$ puede entenderse que no tiene lugar el regreso, en caso de fideiussio: invito reo; in rem suam; donandi animo; pro ignorante (vel absente). ${ }^{36} \mathrm{El}$ último supuesto no viene expresamente previsto en el texto pero se encuentra tratado en D. $17,1,20,1$.

Aunque estos pasajes son aplicables a la fideiussio parecen también propios de la caución bancaria:

Invito reo; supuesto recogido en D. 13,5, 27; no es ejercitable la a. mandati por la sencilla razón de que falta su presupuesto fundamental, esto es, el contrato de mandato. Ni siquiera sería posible la actio negotiorum gestorum si media la expresa prohibición del deudor. ${ }^{37}$

In rem suam; la obligación del garante es, en este caso, sólo formalmente accesoria; en realidad, es la verdadera obligación principal. Al faltar la función típica de la garantía, falta su natural consecuencia que es el regreso a favor del garante. ${ }^{38}$

Donandi animo; tampoco es ejercitable la a. mandati porque falta el presupuesto que es el contrato de mandato. Esta figura se acogerá al régimen jurídico de la donación una vez que el garante haya efectuado el desembolso correspondiente.

Pro ignorante (vel absente); caso previsto en D. 13, 5, 27; el principio aplicable aquí es que no es posible la acción de mandato a favor de quien ha salido fiador por un ausente, no habiendo antecedido el contrato correspondiente. Por otro lado, al fiador se le puede otorgar la acción de gestión de negocios ${ }^{39}$ lo que sería posible extender también al banquero; ésta es una lógica consecuencia siempre que se cumplan los requisitos establecidos para la negotiorum gestio.

C) Beneficium cedendarum actionum: este medio a favor del garante que ha pagado, en lugar de fundarse como la a. mandati sobre una relación entre éste y deudor, se basa en la relación garante-acreedor o en un principio establecido en el ordenamiento jurídico que es expresión de las exigencias de equidad.

De lo anterior se desprende que la cesión de acciones puede tener lugar de dos modos, a saber, voluntariamente, en virtud de negocio ju- 
rídico entre cedente y cesionario, y coactivamente, cuando viene establecida por imperativo legal.

Lo que interesa ahora es la cesión coactiva; que entendemos como aquélla que viene asegurada por el ordenamiento; que se produce mediante un concreto mecanismo procesal y a favor del garante que ha pagado.

En tema de caución bancaria, este beneficio viene asegurado por el texto de D. $17,1,28$, considerado interpolado; el cual presenta no pocas dificultades de interpretación: pero que recoge un principio aplicable a este negocio. ${ }^{40}$

Desde el punto de vista formal, la cesión de acciones tendría lugar mediante la constitución del cesionario como representante procesal ( $\operatorname{cog}$ nitor o procurador) del cedente. ${ }^{41}$

La fórmula presentaría la particularidad de llevar en la intentio el nombre del cedente y en la condemnatio el nombre del cesionario. ${ }^{42}$

En último término, ha de pensarse que, tanto si el reembolso opera mediante el beneficium cedendarum actionum como si tiene lugar en virtud de a. mandati contraria, el argentarius debe tener en cuenta las exigencias de la compensación, si el deudor-cliente es, a su vez, acreedor del banquero. En los iudicia boane fidei la compensatio puede ser operada por el mismo juez. ${ }^{43}$ Así pues, la compensación no figura en la fórmula; las palabras de Gayo 4, 63 parecen indicar que efectuar la compensación entra en el deber, officium, del juez. En cambio, si el argentarius defiende en juicio su crédito a través de la condíctio certae creditae pecuniae, la compensación ha de figurar en la intentio. Gayo 4, 64 ofrece un ejemplo de tal intentio, imaginando que el banquero tiene respecto al mismo cliente un crédito de 20.000 sextercios y un débito de 10.000: Si paret Titium sibi $X$ milia dare oportere amplius quam ipse Titius debet. 


\section{NOT A S :}

1. LENEL, Das Edictum Perpetuum, 1927, p. 132 s.

2. ROSSELLO, Receptum argentariorum, AG 45, 1890, p. 83.

3. PARTSCH, Der Ediktale Garantievertrag durch receptum, ZSS 29, 1908, p. 412.

4. ASTUTI, Il costituto di debito 2, 1941, p. 315.

5. C. 4, 18, 2: Recepticia actione cessante, quae sollemnibus verbis composita inusitato recessit vestigio, necessarium nobis visum est magis pecuniae constitutae naturam ampliare.

6. Los autores antiguos, algunos de los cuales se citan a continuación, usan la denominación a. receptitia; aquí se sigue la terminología que puede leerse en la edición de KRUEGER del Codex Iustinianus.

7. DE ROBERTIS, Receptum nautarum, Annali Bari, 1953, p. 105.

8. Muchos escritores antiguos no se han preocupado de determinar a quién compete la acción, quizá por considerarlo evidente; así, se ha dicho: actio receptitia debatur adversus argentarium qui... CUIACIUS, Paratitl. in Cod. 4, 18, 1758 (II, 194, E); DONELLUS, Comm. ad Cod. 4, 18, 2, 1756 (VII, 994); BRUNS, Das constitutum debiti, Kleinere Schriften, 1882, p. 272. En cambio, otros atribuyen expresamente la acción al acreedor: HEINECCIUS, Elem. iur. sec. Inst., 1759 (I, 256); ORTOLAN, Instit., 1883 (II, 622).

9. La doctrina de los textos interpolados viene siendo generalmente admitida desde LENEL, Beiträge zur Kunde des Edicts und der Edictcommentare, ZSS 1881, p. 62-71.

10. Basado en D. 15, 5, 28 itp.

11. La irrelevancia de la voluntad del deudor principal se desprende del fragmento interpolado D. 13, 5, 27.

12. LENEL, Beiträge, cit., p. 67. Esto mismo lo había dicho ya EISELE, Die Compensation, 1876 , p. 23 y en el mismo sentido se manifiesta KAPPEYNE, Abhandlungen zum römischen Staats und Privatrecht, 1875, p. 275.

13. En esta misma dirección se encuentra VOIGT, Ueber die Bankiers..., 1887, p. 575.

14. PARTSCH, Der Ediktale, cit., p. 412.

15. ASTUTI, Il costituto, cit., p. 315.

16. En este sentido KARLOWA, Röm. R. Gesch., 1885, p. 758.

17. Una confirmación de esto la encontramos en $1.4,6,9: \ldots$ de pecunia constituta cum omnibus agitur, quicumque vel pro se vel pro alio soluturos se constituerit, nulla scilicet stipulatione interposita nam alioquin si stipulandi promiserint, iure civili tenentur.

18. LENEL, EP, cit., n. 95. 
19. LENEL, EP, cit., n. 55 .

20. ZENTNER, De recepto argentariorum, 1859, p. 54.

21. VOIGT, Ueber die Bankiers, cit., p. 575, se manifiesta en oposición a ZENTNER.

22. También en la fideiussio, el fiador responde mediante la acción incierta de estipulación, nunca mediante la acción cierta aunque la deuda principal sea un certum, D. 45, 1, 75, 6 itp.; D'ORS, Der. priv., 1981, p. 510.

23. Esta es la solución prevista por Gayo 4, 137, si se litiga frente a un sponsor o un fideiussor; contra este segundo la prescripción es ea res agatur, quod Ns Ns pro Lucio Titio incertum fide sua esse iussit, cuius rei dies fuit.

24. Fontes I, p. 172.

25. D'ORS, Der. priv., cit., p. 486; es muy posible que el modelo que nos transmite G. 4, 136 no sea constante y admita diversas modificaciones.

26. FREZZA, Le garanzie personali, 1962, p. 281.

27. Gayo 4, 110. Aunque este argumento no es válido para quiènes niegan el carácter civil de la acción.

28. Gayo, 4, 112 .

29. Gayo 3, 121-121 a.

30. Gayo 4, 113.

31. Gayo 3, 120. Praeterea sponsoris et fidepromissoris heres non tenetur, nisi si de peregrino fidepromissore quaeramus, et alio iure civitas eius utatur; no aparece clara cuál puede ser la aplicación de normas de derecho extraño a la fidepromissio.

32. FREZZA, Le garanzie, cit., p. 159.

33. Gayo 3, 127; 4, 22.

34. Sobre la a. mandati contraria en tema de fideiussio, FREZZA, Le garanzie, cit., p. $162 \mathrm{~s}$.

35. Ulpianus libro $X X X V I$ ad edictum: Si passus sim aliquem pro me fideiubere vel alias intervenire, mandati teneor et, nisi pro invito quis intercesserit aut donandi animo aut negotium (suum) gerens, erit mandati actio.

36. FREZZA, Le garanzie, cit., p. 192.

37. D. $17,1,40$.

38. D. $34,3,5,1$.

39. D. $17,1,21$.

40. En cambio, en tema de fideiussio, la cesión coactiva de acciones aparece muy dudosa en las fuentes; y la actio mandati contraria es el medio por excelencia que puede utilizar el garante. FREZZA, Le garanzie, cit., p. 183. 
41. Gayo 2, 39.

42. Gayo 4, 86. Qui autem alieno nomine agit, intentionem quidem ex persona domini sumit, condemnationem autem in suam personam convertit.

43. Gayo 4, 61-68. 